\title{
EFFECT OF HIGH FREQUENCY REPETITIVE TRANSCRANIAL MAGNETIC STIMULATION ON POST STROKE-DYSPHASIA
}

By

\section{Ahmed Bassem Rizk Ali, Nabil Hussein Mohamed and Ahmed Essmat Ali}

Department of Neurology, Faculty of Medicine, Al-Azhar University, Cairo, Egypt

Corresponding Author: Ahmed Bassem Rizk Ali,

Mobile: +201013570287, E-mail: ahmedbassem60789@gmail.com

\begin{abstract}
Background: Aphasia is characterized as language impairment. The bulk of stroke-induced cerebrovascular disease leads to its prevalence. Repetitive transcranial magnetic stimulation (rTMS) is a noninvasive and painless method of altering the excitability of the cerebral cortex by inducing or enhancing neuroplasticity in brain.
\end{abstract}

Objective: The goal of this research to assess the effect of high frequency repetitive transcranial magnetic stimulation (rTMS) on improving post-stroke dysphasia.

Patients and methods: Our studies were conducted on sixty (60) patients suffering from postcerebrovascular stroke dysphasia and were randomly divided into two groups. Group A (case group): Forty patients received stimulatory session's high frequency) of rTMS $(10 \mathrm{~Hz}, 90 \%$ of motor threshold) over the dominant language areas, and Group B (sham group): Twenty patients received sham rTMS on dominant language areas. Patients were selected from the Department of Neurology at Al-Azhar University Hospitals, and follow up was performed at outpatient clinics at (Bab Al-Shaaria and Al-Hussien university hospitals).

Results: There were a significant changes in fluency, auditory verbal (AV) comprehension, sequential commands and aphasia qutions (AQ) before and after rTMS therapy in group A $(\mathrm{P}<0.05)$. There was significant difference in auditory verbal (AV) comprehension, sequential commands before and after shamTMS therapy in group B $(\mathrm{P}<0.05)$.

Conclusion: Significant changes were found in fluency, auditory verbal comprehension, sequential commands and aphasia qutions between before and after TMS therapy in group A (case group).High frequency rTMS was beneficial for rehabilitating patients with post stroke aphasia.

Keywords: rTMS, post stroke dysphasia, WAB scores.

\section{INTRODUCTION}

Aphasia is a severe acquired communication disorder syndrome resulted from damage to the brain language functional areas and related language networks (Worrall and Foster, 2017). Although other causes such as brain tumor, serious infection, or head trauma can also cause aphasia, aphasia happened mostly in patients with cerebrovascular accident (CVA) (Wang and Zhang, 2018).

As one of the most devastating symptoms in CVA survivors, aphasia often leads to a range of communication deficits, including language 
comprehension, language expression, reading, writing, attention, memory, and other cognitive domains (Ellis and Urban, 2016). Aphasia can also cause a series of functional disorders, emotional disorders, social participation disorders, and limitations on activities of daily life that greatly reduce the quality of life (Bullier et al., 2020).

It has been estimated that about 21$38 \%$ of stroke patients develop aphasia. The reported annual incidence of poststroke aphasia in Europe and the United States of America (USA) is 43-60 per 100,000 (Khedr et al., 2020).

Recovery and rehabilitation of language abilities in aphasia has been a challenge for clinicians and researchers, as is evident in a plethora of studies focused on the effectiveness of different therapeutic approaches (Wortman-Jutt and Edwards, 2019).

Repetitive transcranial magnetic stimulation (rTMS) is a noninvasive and painless method of altering the excitability of the cerebral cortex by inducing or enhancing neuroplasticity in brain (Ilkhani et al., 2018).

Growing evidence indicates that rTMS has beneficial effects for patients with aphasia caused by CVA. Stimulating the dominant hemisphere of aphasia patients after CVA with rTMS can improve language functions such as content, fluency, aphasia quotient, dysarthria, repetition, naming performance, expressive language, auditory comprehension, and command comprehension (Zheng et al., 2019).

\section{PATIENTS AND METHODS}

This study was carried out on sixty (60) patients suffering from postcerebrovascular stroke dysphasia and randomly divided into 2 groups:

Group A: Forty patients received stimulatory sessions (high frequency) of rTMS $(10 \mathrm{~Hz}, 90 \%$ of motor threshold) over the dominant language areas according to the patient dysphasia classification based on western aphasia battery (WAB) classification system. Patient received 5 session per week for 2 weeks (10 session totally).

Group B: Twenty patients received sham rTMS on dominant areas.

Patients were selected from the Department of Neurology at Al-Azhar University Hospitals, and follow up was performed at outpatient clinics (Bab AlShaaria and Al-Hussien University Hospitals).

\section{Inclusion criteria:}

1. Stroke confirmed by brain CT or MRI, and the lesions were located within the dominant hemispheric.

2. Duration of stroke of minimum of one month and maximum of three months.

3. The language function of patients met normal population standards before the stroke.

4. The diagnosis of aphasia was made according to western aphasia battery (WAB) standard.

5. The patients were native Arabic speakers.

6. They were right handed (standardized measurement). 


\section{Exclusion criteria:}

1. Patients with recurrent stroke.

2. Their history was positive for language impairment, and their present before the CVA.

3. Stroke was accompanied by severe dysarthria.

4. Language impairment was determined to be caused by other neurodegenerative disorders, such as dementia, Parkinson's disease, motor neuron disease, etc.

5. History of seizures.

6. They possesed comorbid visual or auditory impairments that could influence language performance and the evaluation of language function.

7. They have a metal or electronic device implanted in their body.

Assessment of patients (type of aphasia and follow up) were done by using Western aphasia battery (WAB) scores.
Follow up of aphasic patients was done (before TMS, after 10 sessions of TMS, after 1 month of TMS) by using WAB standard scores.

\section{Statistical analysis:}

Data were collected, revised, coded and entered to the Statistical Package for Social Science (IBM SPSS) version 23. Quantitative data were presented as mean, standard deviations. The Comparison between groups with qualitative data was done by using Chi-square test. The comparison between two groups with quantitative data and parametric distribution were done by using Independent t-test. While data with nonparametric distribution were done by using Mann-Whitney test. The comparison between more than two paired groups with quantitative data and nonparametric distribution was done by using Friedman test.So, P-value was considered significant when $\mathrm{P}$ was $<0.05$.

\section{RESULTS}

Regarding demographic data, there was significant difference between both groups regarding hypertension and ischemic heart disease (Table 1).

Table (1): Comparison between studied groups as regard demographic data and risk factor

\begin{tabular}{|c|c|c|c|}
\hline $\begin{array}{ll}\text { Parameters } & \text { Groups } \\
\end{array}$ & $\begin{array}{c}\text { Group A } \\
(\mathrm{N}=40)\end{array}$ & $\begin{array}{c}\text { Group B } \\
(\mathrm{N}=20)\end{array}$ & P-value \\
\hline $\begin{array}{l}\text { Age (years) } \\
\text { Mean } \pm \text { SD }\end{array}$ & $59.28 \pm 7.51$ & $58.71 \pm 5.68$ & 0.766 \\
\hline Sex & $19(47.5 \%)$ & $12(60 \%)$ & \multirow{2}{*}{0.361} \\
\hline Female & $21(52.5 \%)$ & $8(40 \%)$ & \\
\hline BMI $\left(\mathrm{kg} / \mathrm{m}^{2}\right)$ & & & \\
\hline Mean \pm SD & $26.12 \pm 3.57$ & $25.74 \pm 2.96$ & 0.683 \\
\hline Diabetes & $18(45 \%)$ & $14(70 \%)$ & 0.067 \\
\hline Hypertension & $32(80 \%)$ & $10(50 \%)$ & 0.017 \\
\hline Ischemic heart disease & $15(37.5 \%)$ & $2(10 \%)$ & 0.026 \\
\hline Smoking & $17(42.5 \%)$ & $8(40 \%)$ & 0.853 \\
\hline Hyperlipidemia & $5(12.5 \%)$ & $4(20 \%)$ & 0.443 \\
\hline Atrial fibrillation (AF) & $9(22.5 \%)$ & $4(20 \%)$ & 0.825 \\
\hline
\end{tabular}


There was no statistically significant difference between two groups regarding duration of stroke, type of aphasia and type of stroke (Table 2).

Table (2): Stroke Clinical characteristics of the two studied groups

\begin{tabular}{|c|c|c|c|c|}
\hline \multicolumn{2}{|c|}{ Groups } & $\begin{array}{c}\text { Group A } \\
\text { Characteristics }\end{array}$ & $\begin{array}{c}\text { Group B } \\
(\mathrm{N}=20)\end{array}$ & P \\
\hline \multicolumn{2}{|c|}{$\begin{array}{c}\text { Duration (months) } \\
\text { Mean } \pm \text { SD }\end{array}$} & $1.23 \pm 0.611$ & $1.11 \pm 0.556$ & \multirow{2}{*}{0.351} \\
\hline \multirow{3}{*}{ Aphasia type } & Global & $11(27.5 \%)$ & $6(30 \%)$ & \multirow{2}{*}{0.738} \\
\cline { 2 - 4 } & Motor & $16(40 \%)$ & $6(30 \%)$ & \\
\cline { 2 - 4 } & Sensory & $13(32.5 \%)$ & $8(40 \%)$ & \multirow{2}{*}{} \\
\hline Type & Ischemic & $40(100 \%)$ & $20(100 \%)$ & 1.000 \\
\hline
\end{tabular}

*:Chi-square test; + : Mann Whitney test

There was a statistically significant difference $(\mathrm{P}$-value $<0.05)$ regarding fluency, auditory verbal (AV) comprehension, sequential commands and aphasia qutions (AQ) in group A (Table 3).

Table (3): WAB domains before and after rTMS therapy in group A (case group/ $\mathbf{n}=\mathbf{4 0}$ )

\begin{tabular}{|c|c|c|c|c|}
\hline Therapy & Before & $\begin{array}{c}\text { After 10 } \\
\text { session }\end{array}$ & $\begin{array}{c}\text { After } \\
\text { 1 month }\end{array}$ & P \\
\hline $\begin{array}{c}\text { Fluency } \\
\text { Mean } \pm \text { SD }\end{array}$ & $3.44 \pm 1.73$ & $3.64 \pm 1.78$ & $4.81 \pm 2.75$ & $\mathbf{0 . 0 0}$ \\
\hline $\begin{array}{c}\text { Content } \\
\text { Mean } \pm \text { SD }\end{array}$ & $2.21 \pm 1.12$ & $2.28 \pm 1.17$ & $2.56 \pm 1.39$ & $\mathbf{0 . 1 1 2}$ \\
\hline $\begin{array}{c}\text { AV comprehension } \\
\text { Mean } \pm \text { SD }\end{array}$ & $3.61 \pm 4.02$ & $3.96 \pm 4.01$ & $5.88 \pm 3.83$ & $\mathbf{0 . 0 0}$ \\
\hline $\begin{array}{c}\text { Sequential commands } \\
\text { Mean } \pm \text { SD }\end{array}$ & $3.48 \pm 3.99$ & $3.68 \pm 3.93$ & $5.48 \pm 3.79$ & $\mathbf{0 . 0 0}$ \\
\hline $\begin{array}{c}\text { Repetition } \\
\text { Mean } \pm \text { SD }\end{array}$ & $2.12 \pm 1.56$ & $2.16 \pm 1.57$ & $2.52 \pm 2.01$ & $\mathbf{0 . 0 9 3}$ \\
\hline $\begin{array}{c}\text { Naming } \\
\text { Mean } \pm \text { SD }\end{array}$ & $2.16 \pm 1.63$ & $2.16 \pm 1.63$ & $2.24 \pm 1.64$ & 0.513 \\
\hline $\begin{array}{c}\text { Aphasia qutions(AQ) } \\
\text { Mean } \pm \text { SD }\end{array}$ & $27.92 \pm 20.16$ & $29.43 \pm 20.54$ & $38.75 \pm 23.52$ & $\mathbf{0 . 0 0}$ \\
\hline
\end{tabular}

t: Friedman test

There was a statistically significant difference (P-value $<0.05)$ regarding auditory verbal (AV) comprehension, sequential commands in group B (Table 4). 
Table (4): WAB domains before and after TMS therapy in group B (sham group/ $\mathbf{n}=\mathbf{2 0}$ )

\begin{tabular}{|c|c|c|c|c|}
\hline Parameter & Before & $\begin{array}{c}\text { After } \\
\text { 10 session }\end{array}$ & $\begin{array}{c}\text { After } \\
\text { month }\end{array}$ & P \\
\hline $\begin{array}{c}\text { Fluency } \\
\text { Mean } \pm \text { SD }\end{array}$ & $3.01 \pm 2.02$ & $3.01 \pm 2.02$ & $3.01 \pm 2.02$ & 1.000 \\
\hline $\begin{array}{c}\text { Content } \\
\text { Mean } \pm \text { SD }\end{array}$ & $1.11 \pm 0.876$ & $1.11 \pm 0.876$ & $1.21 \pm .919$ & 0.135 \\
\hline $\begin{array}{c}\text { AV comprehension } \\
\text { Mean } \pm \text { SD }\end{array}$ & $3.71 \pm 4.06$ & $3.71 \pm 4.06$ & $5.01 \pm 4.42$ & $\mathbf{0 . 0 0}$ \\
\hline $\begin{array}{c}\text { Sequential commands } \\
\text { Mean } \pm \text { SD }\end{array}$ & $3.61 \pm 4.12$ & $3.61 \pm 4.12$ & $4.91 \pm 3.38$ & $\mathbf{0 . 0 0}$ \\
\hline $\begin{array}{c}\text { Repetition } \\
\text { Mean } \pm \text { SD }\end{array}$ & $1.01 \pm 0.943$ & $1.01 \pm 0.943$ & $1.11 \pm 0.876$ & 0.135 \\
\hline $\begin{array}{c}\text { Naming } \\
\text { Mean } \pm \text { SD }\end{array}$ & $1.01 \pm 0.943$ & $1.01 \pm 0.943$ & $1.11 \pm 0.876$ & 0.135 \\
\hline $\begin{array}{c}\text { Aphasia qutions } \\
\text { Mean } \pm \text { SD }\end{array}$ & $22.13 \pm 15.76$ & $22.13 \pm 15.76$ & $27.03 \pm 18.79$ & $\mathbf{0 . 0 7 8}$ \\
\hline
\end{tabular}

t: Friedman test

There was 5 patients $(12.5 \%)$ suffered from headache in group A and no patients suffered from complications in group B but without statistical significance difference (Table 5).

Table (5): Complications distribution among the two studied groups

\begin{tabular}{|c|c|c|c|}
\hline $\begin{array}{ll}\text { parameters } & \text { Groups } \\
\end{array}$ & $\begin{array}{c}\text { Group A } \\
(\mathrm{N}=40)\end{array}$ & $\begin{array}{c}\text { Group B } \\
(\mathrm{N}=20)\end{array}$ & $\mathbf{P}$ \\
\hline No complication & $35(87.5 \%)$ & $20(100 \%)$ & \multirow{2}{*}{0.099} \\
\hline Headache & $5(12.5 \%)$ & 0 & \\
\hline
\end{tabular}

\section{DISCUSSION}

Our study results showed that a significant change in fluency, auditory verbal comprehension, sequential commands and aphasia qutions were found between before and after TMS therapy in group A. There was significant difference in WAB scores for $\mathrm{AV}$ comprehension, sequential commands between before and after sham TMS in group B.

The results of current study were supported by Ren et al. (2019) who showed that the changes in spontaneous speech, auditory comprehension, AQ, and repetition were significantly higher in the
rTMS-w, and rTMS-b groups compared with sham group. The effect of rTMS may depend on the stimulation site. Low frequency rTMS inhibited the right pSTG and significally improved language recovery in terms of auditory comprehension and repetition, whereas LF-rTMS inhibited the right pIFG leading to significant changes in spontaneous speech and repetition.

In accordance with our results, Xia et al. (2018) investigated the effects of High frequency repetitive transcranial magnetic stimulation (rTMS) of the motor cortex on non-fluent aphasia in patients after stroke. After the treatment, the average score of 
the auditory comprehension, repetition, naming and AQ of the rTMS group were significantly higher than those of the control group.

Hu et al. (2018) examined the efficacy of different frequencies of rTMS applied to the contralesional hemisphere in stroke patients with non-fluent aphasia. Patient's language ability was assessed prior to, immediately after and 2 month post treatment by WAB scores. Greater improvement was noted for the lowfrequency rTMS group in spontaneous speech, auditory comprehension and AQ as compared to the high-frequency group, even 2 months post- treatment. High frequency rTMS cohort exhibited significant improvement at 2 months posttreatment in repetition and AQ. LF-rTMS produced immediate benefits that persisted long term, while HF-rTMS only produced long term benefit. In addition, the benefits produced with LF were more than produced by HF.

\section{CONCLUSION}

Significant changes occurred in fluency, auditory verbal (AV) comprehension, sequential commands and aphasia qutions was found between before and after HF rTMS in patients group.

High frequency rTMS was beneficial for rehabilitating patients with post stroke aphasia.

Conflicts of interest: No conflicts of interest were encountered.

\section{REFERENCES}

\section{Bullie B, Cassoudesalle $H$, Villain $M$,} Cogné M, Mollo C, De Gabory I and Glize B (2020): New factors that affect quality of life in patients with aphasia.
Annals of Physical and Rehabilitation Medicine, 63(1): 33-37.

2. Ellis C, and Urban S (2016): Age and aphasia: a review of presence, type, recovery and clinical outcomes. Topics in Stroke Rehabilitation, 23(6): 430439.

3. Hu Y, Zhang T, Rajah B, Stone C, Liu $X$, He J, and Yang $Q$ (2018): Effects of different frequencies of repetitive transcranial magnetic stimulation in stroke patients with nonfluent aphasia: a randomized, shamcontrolled study. Neurological Research, 40(6): 459-465.

4. Ilkhani M, Baghini S, Kiamarzi G, Meysamie A and Ebrahimi P (2018): The effect of low-frequency repetitive transcranial magnetic stimulation (rTMS) on the treatment of aphasia caused by cerebrovascular accident (CVA). Medical journal of the Islamic Republic of Iran, 32:25-29.

5. Khedr M, Abbass A, Soliman $\mathbf{K}$, Zaki F, Gamea A, El-Fetoh A, and Abdel-Aaal A (2020): A hospitalbased study of post-stroke aphasia: frequency, risk factors, and topographic representation. The Egyptian Journal of Neurology, Psychiatry and Neurosurgery, 56(1): 2.

6. Ren C, Zhang G, Xu X, Hao J, Fang H, Chen $P$ and Gao F (2019): The effect of rTMS over the different targets on language recovery in stroke patients with global aphasia: a randomized sham-controlled study. BioMed Research International, 52:243-249.

7. Wang J, Li J, and Zhang Y (2018): Effects of low frequency repetitive 
transcranial magnetic stimulation on non-fluent aphasia after stroke. Chin J Rehabil Med, 33:1463-4.

8. Worrall $L$ and Foster A (2017): Does intensity matter in aphasia rehabilitation? Lancet (London, England), 389(10078): 1494-1495.

9. Wortman-Jutt $S$ and Edwards D (2019): Poststroke aphasia rehabilitation: Why all talk and no action? Neurorehabilitation and Neural Repair, 33(4): 235-244.

10. Xia J, Xu Q, Zhang Q, Chen Z, Chen Y, Lu Y, and Cheng Y (2018): High frequency repetitive transcranial magnetic stimulation of the motor cortex can alleviate non-fluent aphasia after stroke. Annals of Physical and Rehabilitation Medicine, 61: e259.

11. Zheng Y, Zhong D, Huang Y, He M, Xiao Q, Jin R, and Li J (2019): Effectiveness and safety of repetitive transcranial magnetic stimulation (rTMS) on aphasia in cerebrovascular accident patients: Protocol of a systematic review and meta-analysis. Medicine, 98:52-60. 
تأثير التحفيز المغناطيسى المتكرر عبر الجمجمة عالى التردد

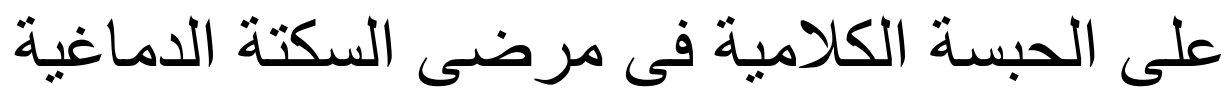

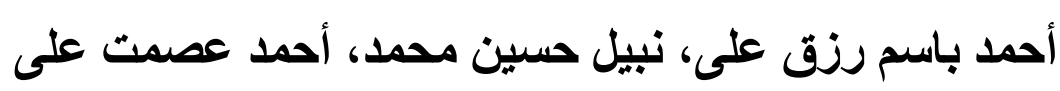

قسم طب المخ والاعصاب، كلية الطب، جامعة الأزهر، القاهرة

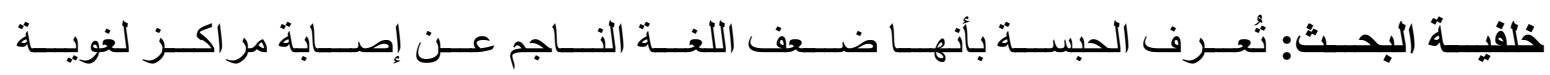

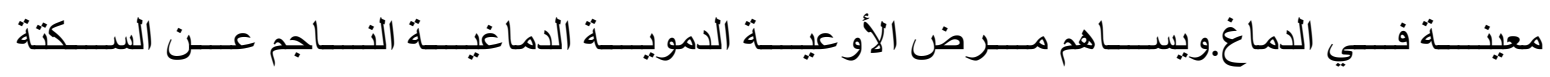

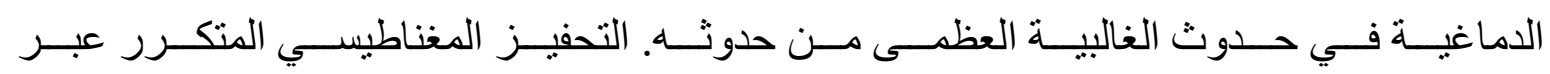

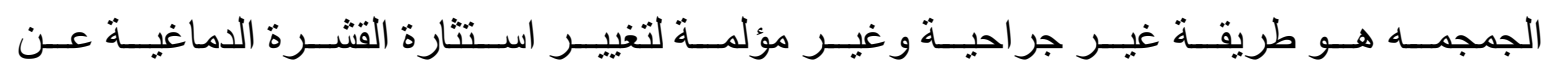
طريق تحفيز المرونة العصبية في الدماغ أو تعزيز ها.

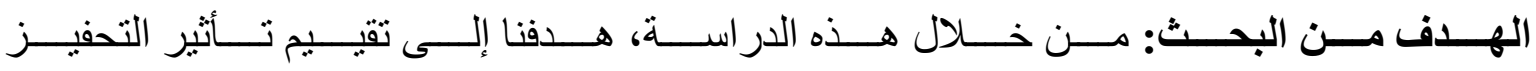

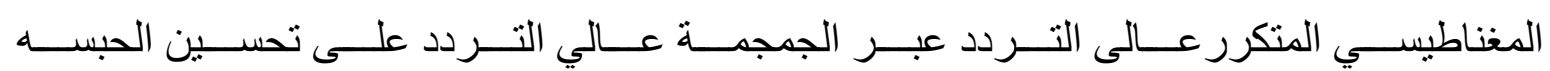
الكلاميه عند مرضى السكتة الدماغية.

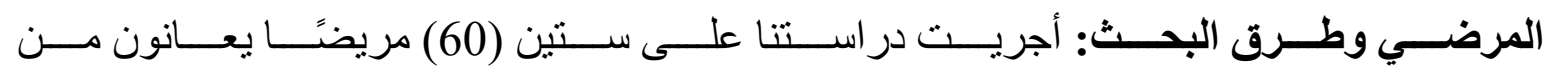

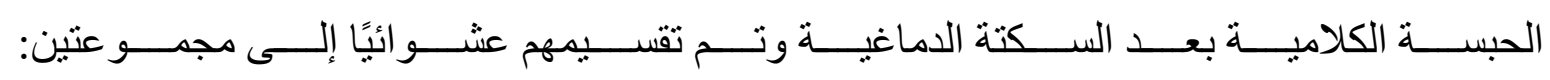

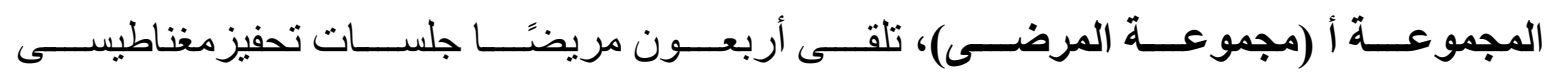

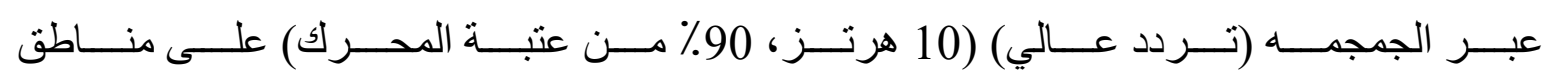

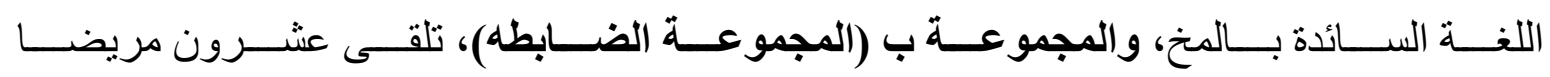

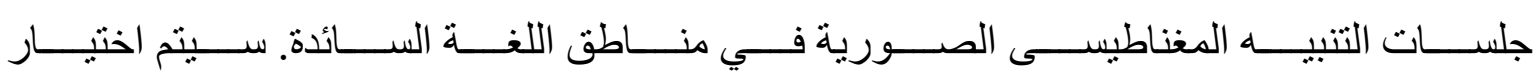

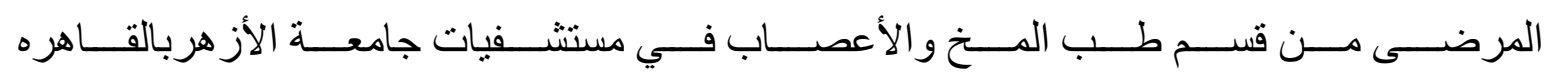

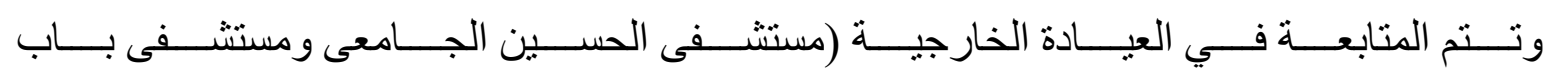

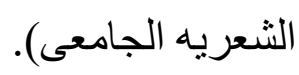

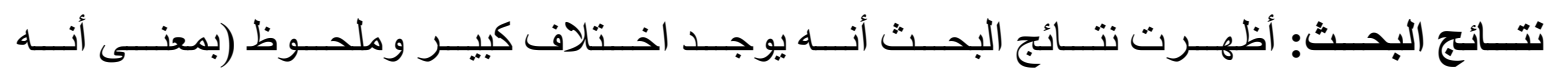

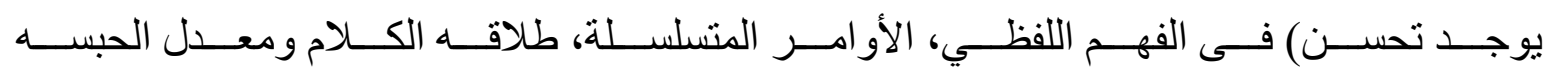
الكلامية قبل وبعد العلاج بالتحفيز المغناطيسى عالى التردد في المجمو عة (أ). 


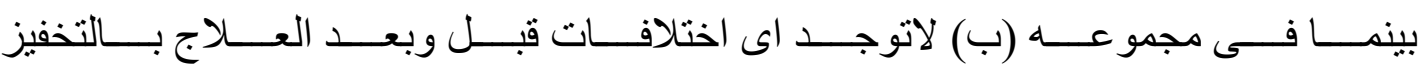
المغناطيسى الصورى.

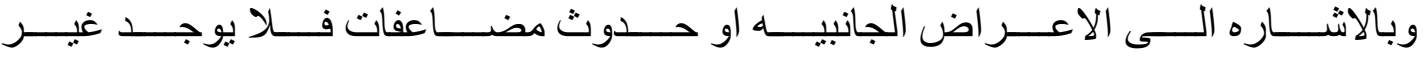

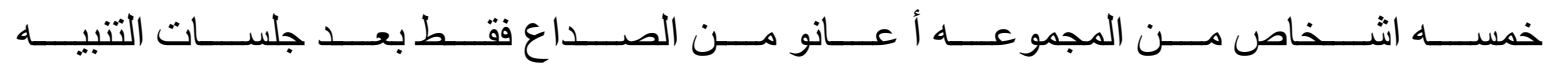
المغناطيسى وفد تحسنو ف خلال ايام بالمسكنات الخفيفه.

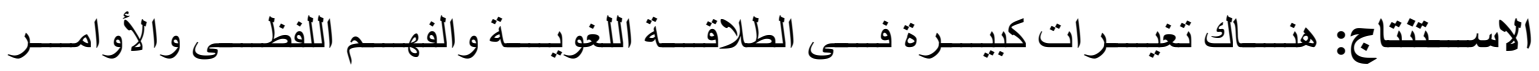

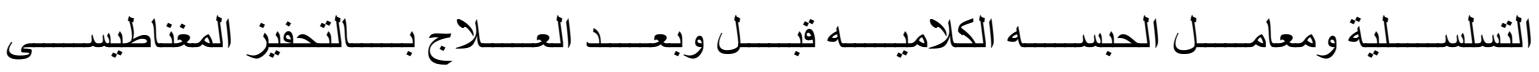
المتكرر عالى التردد عبر الجمجمه فى المجموعه (أ).

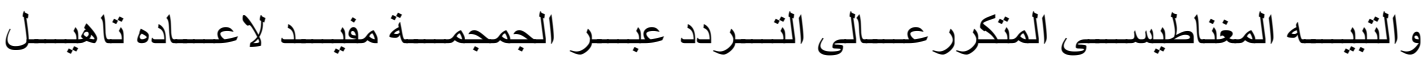

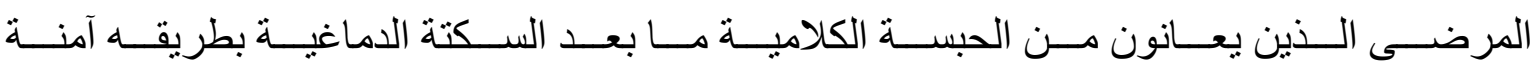
و غير مؤلمة.

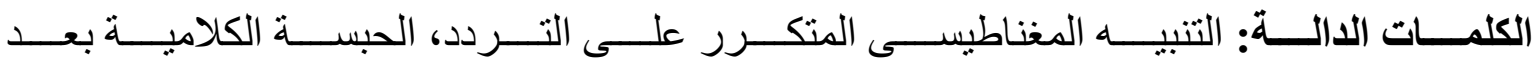
السكتة الدماغية، اختبار معامل الحبسه. 